\title{
Validation of the student athletes' motivation towards sports and academics questionnaire to Korean student- athletes
}

\author{
Sunghee Park', Seungbun Hong ${ }^{2 *}$, Miyoung Lee ${ }^{3}$ \\ ${ }^{1}$ Performance Psychology Center, Kwangwoon University, Seoul, South Korea \\ ${ }^{2}$ Graduate School of Education, Yongin University, Yongin, Korea \\ ${ }^{3}$ College of Physical Education and Sport Science, Kookmin University, Seoul, Korea.
}

The current study had three aims: (1) to validate a Korean version of the Student Athletes' Motivation toward Sports and Academics Questionnaire (SAMSA0-Kr), (2) to examine South Korean university student-athletes' motivation towards athletic and academic achievement, and (3) to identify the relationship between athletic identity and their athletic and academic achievement. A total of 126 South Korean university student-athletes ( $41.4 \%$ males and $58.6 \%$ females; mean age 20.5 , $S D=2.74)$ completed the SAMSAQ-Kr. To investigate the validity evidence of the SAMSAQ-Kr a confirmatory factor analysis (CFA) and Rasch model were employed. To examine the relationship between Athletic Identity Measurement Scale (AIMS) and SAMSAO for Spear- man correlation coefficients were calculated. Findings indicated that the SAMSA0-Kr showed a different model from other versions and revealed positive correlations between AIMS scores and athletic motivations. The current study highlighted that importance of considering socio-cultural context in developing questionnaire and contributed to help understand South Korean university student-athletes' motivation towards athletic and academic achievement.

Keywords: Academic motivations, Athletes' dual-careers, Athletic identity, Athletic motivations

\section{INTRODUCTION}

Early sport psychology research examination focused on performance enhancement (Stambulova et al., 2006). Overtime this focus has shifted and since the 1990's athletes' quality of life and life skills development has been received attention. Athletes' career transition has emerged as an essential area related to athletes' life skills development and quality of life regardless of the type of sport or competition level as almost all elite athletes experience both within career transitions and transition out of their sports (Bruner et al., 2008; Harrison and Lawrence, 2004). Therefore, studies examining athletes' career transitions have increased gradually for the past three decades.

Researchers have become interested in identifying factors that influence the quality of athletes' career transitions, reporting that causes of career transition, individuals' life skills development, and coping resources are related to athletes' post-sport life adjustment (Park et al., 2013). Furthermore, athletes' work-life balance could be one of the main factors related to athletes' life skills development such as gaining educational qualifications, developing multiple identities, as well as occupational skills (Park et al., 2013). Previous research (Stephan and Brewer, 2008) has indicated that elite athletes tend to have a high degree of athletic identity. Some athletes even showed identity foreclosure referring to "a state of identity in which individuals make commitments to roles without engaging in exploratory behavior". Researchers (Stephan and Brewer, 2008) have attributed elite athletes' high degree of athletic identity to a devotion to their sport, in which these athletes' are
${ }^{*}$ Corresponding author: Seungbun Hong

Graduate School of Education, Yongin University, 134 Yongin Daehakro, Cheoin$\mathrm{gu}$, Yongin 17092, Korea

Tel: +82-10-4927-3125, Fax: +82-31-8020-2891, E-mail: shong528@gmail.com

Received: May 11, 2015 / Accepted: August 5, 2015
This is an Open Access article distributed under the terms of the Creative Commons Attribution Non-Commercial License (http://creativecommons.org/licenses/by-nc/3.0/) which permits unrestricted non-commercial use, distribution, and reproduction in any medium, provided the original work is properly cited. 
dedicated to achieving their sporting goals, spend most of their time and effort training and in competition, and prioritize their sport above all other aspects of their lives. Whilst some researchers (Anderson, 2004; Werthner and Orlick, 1986) have identified that to become elite performers, athletes must sacrifice their time, and their effort levels must be high, negative influences, limitations of an unbalanced lifestyle and strong athletic identity require consideration given their potential impact (Stephan and Brewer, 2008).

A current area of research examination is athletes' ability to manage other demands outside of their sport simultaneously due to its influence on athletes work-life balance. For example, student-athletes' coping with the demands of developing their athletic and academic careers. Dealing with life demands simultaneously has been highlighted in particular for student-athletes, with previous research findings (Fortes et al., 2010) indicating that some student-athletes who have dual careers (i.e., academic and athletic careers) focus on their athletic careers rather than having a more balanced approach to the athletic and academic careers. In addition, researchers (Guidotti et al., 2013) have suggested that student-athletes' who devoted highly in their sport might show a low academic achievement because athletes' who put priority to their sports usually have high motives for their athletic success rather than academic achievement and subsequently less effort is given to their academic career.

The interest in athletes' dual careers is not just for academics but also practitioners. As a result, many sport institutes around the World are interested in athletes' dual careers to develop their multiple identities and life skills in addition to their educational achievement. Recently, the European Parliament has highlighted the importance of considering student-athletes' work-life balance between athletic and academic careers. Student-athletes ability to cope with their dual careers is critical to the lifespan development and post-sport career adjustment. The European Parliament have also established guidelines for "Education and Training in Sport" for athletes' dual careers and have encouraged sport governing bodies to support student-athletes' academic development (Guidotti et al., 2013). However, research examination of athletes' dual careers is still in its infancywith only few studies to date (Gaston-Gayles, 2005; Guidotti et al., 2013) that have examined whether certain variables that can predict student-athletes' balance between academic and athletic development.

One study (Gaston-Gayles, 2005) in this research area, aimed to develop Student Athletes' Motivation toward Sports and Academics Questionnaire (SAMSAQ). Gaston-Gayles (2005) exam- ined American student-athletes' academic, athletic, and athletic-career motivation reporting that male student-athletes had lower academic achievement than female colleagues, and that non-Caucasian student-athletes had higher athletic motivation than Caucasian student-athletes. Forte et al. (2010) later employed the SAMSAQ to examine student-athletes' athletic and academic motivation in the United Arab Emirates of Dubai. In contrast to Gaston-Gayles (2005) they reported that in Arab Emirates, male student-athletes had a higher academic motivation than female student-athletes. They also concluded that student-athletes from Arab Emirates had higher motivation for their academic careers compared to their athletic career because of the importance of their post-university career choices. Finally, a European study (Guidotti et al., 2013) examined student-athletes at Italian University, reporting no demographical differences (gender, race) as in the two studies above. However, Guidotti et al. (2013) did report that Italian student-athletes' degree of academic motivation was similar to the American student-athletes sampled in Gaston-Gayles's (2005) study. However, it should be noted that the questionnaire items for each underlying factors were grouped differently from the American version. Therefore, the differences observed between the studies above could be explained by socio-cultural influences and the sport and academic contexts where student-athletes belong to in terms of their social support networks, values of academic or athletic achievement and support systems for dual careers.

Another recent emergence of interest in student-athletes' academic achievement and variables related to student-athletes' dual careers has come from South Korean politicians and the Korean Olympic Committees, due to high unemployment rates among retired elite athletes and a lack of support systems (Korean Olympic Committee report, 2012). Consequently, in 2013 a new law for monitoring and supporting student-athletes' academic involvement was established. However, no research to date has examined South Korean student-athletes' motivation towards their athletic and academic careers and at present an appropriate measure does not exist. Developing a Korean version of SAMSAQ will allow researchers to identify Korean student-athletes' motivation toward their sports and academic achievement. Thus developing appropriate measurement tools and examining homogeneous samples from different cultures is warranted because of cultural and environmental influences on athletes' life skills development and quality of lives (Si et al., 1995). Additionally, given that athletic identity has been suggested as influencing athletes' work-life balance, examining relationships between the degree of stu- 
dent-athletes' athletic identity and academic motivation might offer highlight help provide ways to assist student-athletes to balance their athletic and academic careers.

The current study had three aims. The first aim was to develop and validate Korean version of SAMSAQ for South Korean student-athletes. The second aim was to examine their degree of motivation toward athletic and academic careers. The third aim was to identify relationships between a degree of athletic identity and academic motivation among South Korean student-athletes.

Based on the previous research findings (Forte et al., 2010; Gaston-Gayles, 2005; Guidotti et al., 2013), it was hypothesized that (a) the Korean version of SAMSAQ might be composed with a different construct from the original version due to social-cultural language differences, (b) South Korean student-athletes might have a high athletic motivations than academic motivation, and (c) a degree of athletic identity might have a positive relationships with athletic motivation since it explains values of their sports for athletes.

\section{MATERIALS AND METHODS}

\section{Instrument}

Student Athletes' Motivation toward Sports and Academics Questionnaire (SAMSAQ; Gaston-Gayles, 2005) was developed in America based on Achievement Motivation Theories (Atkinson, 1974), Expectancy Value Theory, and Self-Efficacy Theory (Bandura, 1977) to examine student-athletes' motivation toward sports and academic achievement. The questionnaire initially contained 30 items on a 6-point Likert scale, ranging from very strongly agree (6) to very strongly disagree (1), and has three subscales: Student-Athletic Motivation (SAM); Career Athletic Motivation (CAM); and Academic Motivation (AM). Gaston-Gayles (2005) reported that the SAMSAQ has high internal consistency coefficients for the three subscales (SAM: $\alpha=0.86$; CAM: $\alpha=0.84$; AM: $\alpha=0.79)$. Based on the original English version of SAMSAQ, a Korean version (SAMSAQ-Kr) was developed through translation from the English version to Korean by authors of the current study and was subsequently reverse translated from Korean to English by two independent researchers to ensure the translation process was accurate.

Athletic Identity Measurement Scale (AIMS; Brewer et al., 1993) was employed to examine athletes' degree of athletic identity. The scale contains 10 items on a 7-point Likert scale ranging from strongly disagree (1) to strongly agree (7) and contains questions related to social identity, exclusivity, and negative affectivity.
Brewer and Cornelius (2001) reported that the scale has high internal correlation coefficient $(\alpha=0.81-0.93)$.

\section{Participants}

A total of 126 South Korean university student-athletes (41.4\% males and $58.6 \%$ females; mean age 20.5, SD=2.74) completed the SAMSAQ-Kr. All 126 participants were tennis players who have competed for more than $10 \mathrm{yr}$, a total participants for the current study is a $58 \%$ of the total population of registered university tennis players in Korea. Of the total sample, 31 were international level competitors, 92 competed domestically, and $3 \mathrm{did}$ not report their level of competition. There were two main reasons why tennis players were sampled. First, tennis is a popular individual sport in South Korea and there are both semi- and professional teams around the nation, which are the potential post-university sporting careers for student-athletes. Second, it was reported at the national assembly in 2013, that there is a higher unemployment rate amongst retired tennis players compared with retired athletes from other sports registered in Korean Olympic Committee ("Hundred", 2013).

\section{Procedure}

The SAMSAQ was translated into Korean by two experts in Kinesiology, which was sport psychologist and measurement specialist, respectively, and then it was reverse translated back to English as suggested by Su and Parham (2002). After the SAMSAQ-Kr was developed the Korean Tennis Association were contacted and asked to provide tournament schedules for the university student-athletes.

Data were collected between August and November 2013 through four different tennis tournaments in South Korea. On meeting the participants, the researchers explained the aims of the study and provided instructions of how to complete the questionnaires. After that the SAMSAQ-Kr and AMIS were distributed to the university student-athletes, which took them approximately 20 minutes to complete.

\section{Data analysis}

Descriptive analysis was applied for the demographic information. To investigate the validity evidence of SAMSAQ-Kr whether the items show the same construct with the original version of the questionnaire, a confirmatory factor analysis (CFA) and Rasch model were employed. The criteria of the goodness-of-fit for CFA were followed by Guidotti et al. (2013), which we revalidating SAMSAQ to the Italian athletes. The index of the model fit in- 
cluded chi square $\left(\chi^{2}\right)$, comparative fit index (CFI), goodness of fit index (GFI), normed fit index (NFI), root mean square error of approximation (RMSEA). Rasch analysis was applied to examine the unidimensionality and to determine the item difficulty (i.e., level of motivations) and participant's ability (motivation), in which the Rasch rating model employs a log-odds (logit) transformation to convert the ordinal scale to an interval scale of SAMSAQ-Kr (Hart and Wright, 2002; Wright et al., 1997; Zhu and Cole, 1996). Goodness-of-fit index of the Rasch model includes infit and outfit between 0.5 and 1.5. The CFA was performed by AMOS 16 (IBM SPSS Inc.), and Rasch analysis was calculated by WINSTEPS 3.64.2. To determine the reliability evidence of the developed items, Cronbach's alpha was computed.
To examine the relationship between AIMS and SAMSAQ, Spearman correlation coefficients were calculated. To determine the group differences of gender and performance level (international vs. general), independent t-test was calculated. Except for CFA and Rasch analysis, SPSS 20 (IBM SPSS Inc.) was utilized and all alpha level $(\alpha)$ was set at 0.05 .

\section{RESULTS}

The validity and reliability evidences of the SAMSAQ-Kr were displayed in Table 1 including the results of CFA, Rasch analysis, and Cronbach's alpha, respectively. From CFA, it was revealed that eight items of AM, two items of CAM, and three items of SAM

Table 1. Results of validity and reliability evidences for the SAMSAQ-KR

\begin{tabular}{|c|c|c|c|c|c|c|c|c|}
\hline \multirow{2}{*}{$\begin{array}{l}\text { Item\# } \\
\text { US }\end{array}$} & \multirow{2}{*}{$\begin{array}{c}\text { Item\# } \\
\text { KR }\end{array}$} & \multirow{2}{*}{$\begin{array}{c}\text { SAMSAO } \\
\text { US }\end{array}$} & \multirow{2}{*}{$\begin{array}{c}\text { SAMSAO } \\
\text { KR }\end{array}$} & \multirow{2}{*}{$\begin{array}{c}\text { CFA } \\
\text { Factor loading }\end{array}$} & \multicolumn{3}{|c|}{ Rasch Analysis } & \multirow{2}{*}{ Cronbach o } \\
\hline & & & & & Logit & Infit & Outfit & \\
\hline 1 & 1 & AM1 & AM1 & 0.63 & 0.08 & 1.25 & 1.27 & 0.849 \\
\hline 2 & 2 & AM2 & AM2 & 0.61 & -0.14 & 1.1 & 1.12 & \\
\hline 3 & 3 & AM3 & AM3 & 0.78 & -0.16 & 1.13 & 1.19 & \\
\hline 4 & & AM4 & misfit & & & & & \\
\hline 5 & & AM5 & misfit & & & & & \\
\hline 6 & & AM6 & misfit & & & & & \\
\hline 7 & & AM7 & misfit & & & & & \\
\hline 8 & & AM8 & misfit & & & & & \\
\hline 9 & & AM9 & misfit & & & & & \\
\hline 10 & & AM10 & misfit & & & & & \\
\hline 11 & 4 & AM11 & AM11 & 0.57 & 0.12 & 1.06 & 1.05 & \\
\hline 12 & & AM12 & misfit & & & & & \\
\hline 13 & 5 & AM13 & AM13 & 0.53 & -0.15 & 0.68 & 0.7 & \\
\hline 14 & 6 & AM14 & AM14 & 0.5 & 0.15 & 1.29 & 1.32 & \\
\hline 15 & 7 & AM15 & AM15 & 0.81 & -0.16 & 1.09 & 1.09 & \\
\hline 16 & 8 & CAM1 & CAM1 & 0.25 & -0.04 & 1.02 & 1.07 & 0.703 \\
\hline 17 & & CAM2 & misfit & & & & & \\
\hline 18 & 9 & CAM3 & CAM3 & 0.6 & 0.31 & 0.91 & 0.92 & \\
\hline 19 & 10 & CAM4 & CAM4 & 0.89 & 0.42 & 1.38 & 1.38 & \\
\hline 20 & 11 & CAM5 & CAM5 & 0.8 & 0.3 & 1.03 & 1.03 & \\
\hline 21 & & CAM6 & misfit & & & & & \\
\hline 22 & 12 & SAM1 & SAM1 & 0.6 & 0.03 & 0.78 & 0.79 & 0.857 \\
\hline 23 & & SAM2 & misfit & & & & & \\
\hline 24 & & SAM3 & misfit & & & & & \\
\hline 25 & 13 & SAM4 & SAM4 & 0.75 & -0.32 & 0.96 & 0.96 & \\
\hline 26 & 14 & SAM5 & SAM5 & 0.7 & 0 & 0.7 & 0.7 & \\
\hline 27 & 15 & SAM6 & SAM6 & 0.85 & -0.03 & 0.63 & 0.62 & \\
\hline 28 & & SAM7 & misfit & & & & & \\
\hline 29 & 16 & SAM8 & SAM8 & 0.64 & -0.25 & 1.2 & 1.21 & \\
\hline 30 & 17 & SAM9 & SAM9 & 0.7 & -0.16 & 0.68 & 0.68 & \\
\hline
\end{tabular}


Table 2. Group differences of variables

\begin{tabular}{|c|c|c|c|c|c|c|c|c|c|c|}
\hline & \multicolumn{2}{|c|}{ Male $(n=74)$} & \multicolumn{2}{|c|}{ Female $(n=52)$} & \multirow{2}{*}{$P$} & \multicolumn{2}{|c|}{ International $(n=31)$} & \multicolumn{2}{|c|}{ General $(n=92)$} & \multirow{2}{*}{$P$} \\
\hline & $\mathrm{M}$ & SD & M & SD & & M & SD & $\mathrm{M}$ & SD & \\
\hline AGE & 20.93 & 2.62 & 20.16 & 2.79 & & 20.81 & 3.11 & 20.49 & 2.94 & \\
\hline AIMS & 4.50 & 1.01 & 5.05 & 1.00 & $* * *$ & 5.49 & 1.20 & 4.67 & 0.94 & $* * *$ \\
\hline AM & 3.71 & 0.97 & 3.85 & 0.77 & & 3.93 & 0.77 & 3.74 & 0.90 & \\
\hline SAM & 3.82 & 0.98 & 4.02 & 0.81 & & 4.21 & 1.02 & 3.87 & 0.88 & \\
\hline CAM & 3.56 & 0.98 & 3.49 & 0.92 & & 4.01 & 1.03 & 3.44 & 0.89 & * \\
\hline SAMSAO & 3.74 & 0.69 & 3.75 & 0.56 & & 4.03 & 0.60 & 3.69 & 0.62 & * \\
\hline
\end{tabular}

$\mathrm{M}=$ Mean, $\mathrm{SD}=$ Standard deviation, ${ }^{* * *} P<0.001,{ }^{*} P<0.05$.

Table 3. Spearman's Rho coefficients of AIMS and SAMSAO

\begin{tabular}{lccccc}
\hline & & AM & SAM & CAM & SAMSA0 \\
\hline Overall & AIMS & 0.091 & 0.652 & 0.514 & 0.575 \\
& AM & & 0.192 & 0.106 & 0.469 \\
& SAM & & & 0.678 & 0.848 \\
& CAM & & & & 0.830 \\
Male & AIMS & -0.025 & 0.521 & 0.548 & 0.460 \\
Female & AIMS & 0.181 & 0.768 & 0.511 & 0.680 \\
International & AIMS & -0.423 & 0.719 & 0.622 & 0.577 \\
General & AIMS & 0.102 & 0.595 & 0.466 & 0.522 \\
\hline
\end{tabular}

were misfit for the South Korean student-athletes. After removing these misfit items from the data pool, CFA was re-applied and Rasch analysis was performed, then all items showed within the index of goodness-of-fit. Overall reliability coefficients of sub-constructs (e.g., AM, CAM, and SAM) showed moderate high to high internal consistency $(\alpha=0.703-0.857)$ (Table 1).

Using 'good' 17 items and AIMS, group differences of the gender and performance levels were examined (Table 2). Both of genders and performance level groups showed statistically significant differences in AIMS (Male < Female vs International > General, $P<0.001)$. Even though females showed higher SAMSAQ, there was no statistical difference. On the other hand, international experienced students showed high scores on all SAMSAQ sub-construct items than general athletes, but only CAM and the overall SAMSAQ-Kr showed statistically significant differences between groups $(P<0.05)$ (Table 2$)$.

The correlation coefficients between AIMS and SAMSAQ were provided in Table 3. Among the sub-constructs of SAMSAQ, SAM and CAM showed relatively high correlation $(P=0.652$ and 0.514 , respectively), but little correlation between AM and AIMS. When the correlation coefficients were calculated by groups separately, the relationship between AIMS and SAMSAQ was higher in female and in international group. Interestingly, the international group showed negative relationship between AM and AIMS (Table 3).

\section{DISCUSSION}

The current study had three aims: (1) to validate a Korean version of the SAMSAQ, (2) to examine South Korean university student-athletes' motivation towards athletic and academic achievement, and (3) to identify the relationship between athletic identity and their athletic and academic achievement.

Based on the Confirmatory Factor Analysis and Rasch analysis, the Korean version of the SAMSAQ (SAMSAQ-Kr) showed a different construct from those of American, Arab Emirates, and Italian version. The final version of SAMSAQ-Kr contains a total of 17 items with three subscales, AM (7 items), SAM (6 items), and CM (4 items). These result supported Guidotti et al.'s (2013) findings which highlighted differences between the SAMSAQ original English version and the Arab Emirates and Italian versions. Researchers (Guidotti et al., 2013; Su and Parham, 2002) have argued that there is a need for validated version of models which are appropriate for different language and populations due to cultural differences. Therefore, the current findings contribute to understanding South Korean university student-athletes' motivation towards athletic and academic achievement through validating SAMSAQ-Kr as providing acceptable validity and reliability evidences.

The results revealed that there was no gender difference in SAMSAQ-Kr score among South Korean university student-athletes, however, differences were found between competition levels International level student-athletes showed significantly higher CAM score as well as overall SAMSAQ-Kr score comparing to general level participants those who compete in domestically. This 
result indicated clear differences in the sub-constructs of a SAM and a CM, highlighted by Gaston-Gayles (2005) in terms of providing expectations in participants' desire to seek athletic achievement for the current status (SAM) and future athletic careers (CM). The results also suggest student-athletes who are competing at a high level tended to have higher motivation and seek opportunities to play at a professional level compared to general level athletes.

Regarding the significant differences in mean SAMAQ-Kr score between athletic levels, the results can be explained using the basic framework of the original SAMSAQ, which are Achievement Motivation Theories (Atkinson, 1974). According to researchers (Atkinson, 1974), there are different tendencies between high achievers and low achievers. Generally high performers have a high achievers' tendency and greater motivation to challenge and succeed in reaching their goals. Thus, the current findings support these suggestions, as the international level participants' high motivation scores can be explained due to their high achievers' disposition.

Regarding the relationship between AIMS and SAMSAQ-Kr scores, positive correlations were found between AIMS scores and SAM and CAM scores. Additionally, international level athletes had a higher AIMS score than athletes in a general level, competing domestically. This finding echoes previous study findings (Brewer et al., 1993; Stephan and Brewer, 2008), as the student-athletes' degree of athletic identity can be a barrier to achieving a balance between athletic and academic motivation whilst at university.

The current findings indicated that South Korean university student-athletes' overall SAMSAQ-Kr score was generally lower than American and Italian participants in previous studies (Gaston-Gayles, 2005; Guidotti et al., 2013). Compare to Arab Emirate student-athletes (Forte et al., 2010), South Korean student-athletes showed higher athletic motivation but lower academic motivation. As discussed in previous studies (Fortes et al., 2010; Guidotti et al., 2013), because the participants from Arab Emirates were mixture of student-athletes and non-athletes, and they tended to focus highly on finding post-university occupations, they appeared to have a lower motivation for an athletic career.

Whilst Fortes et al. (2010) concluded that student-athletes from Middle-East tended to have higher academic motivation then American counterparts after comparing their findings from Arab Emirates participants to previous findings from America, current study findings contradict this previous comparison. South Korean student-athletes' academic motivation was even lower than those American and Italian samples, and this could be caused by poor South Korean sporting and education systems for elite athletes. For the past few decades, there has been inadequate support or monitoring systems to assist student-athletes' academic performance and progress in South Korea, thus the majority of athletes did not have a balance between education and sport training. For the past few years, elite athletes' life balance including formal education whilst studying has been discussed among academics and politicians, and it has been highlighted that when student-athletes did not engage in formal education during elementary and secondary school, they would not have an interest in academic achievement whilst at university (Jang, 2010). The current findings might support the argument that a lack of educational involvement in earlier student period might cause low academic motivation during the university time. Therefore in South Korea, to help athletes to develop balanced lifestyles and their life skills, laws and protection systems for student-athletes' educational rights was established in 2013. Similar to studies from Arab Emirates and Italy, no gender difference was found in academic and athletic motivation among South Korean student-athletes. Regarding competition level, the current findings supports Guidotti et al.'s (2013) study with Italian athletes which showed that high level student-athletes had higher SAM and CM scores than those who competed at a lower level. Moreover, because the current study examined a degree of athletic identity, the current findings provides greater understanding of the relationships between a degree of athletic identity and athletic motivation. Thus, current study findings may explain why student-athletes competing at a higher level may have greater desire for athletic success and to become professional athletes than those competing at a lower level.

The current study has several limitations. Although the data were collected from South Korean university tennis players, the sample size is relatively small. Therefore, the sample size of the current study might influence on the validity evidence of the SAMSAQ-Kr. Furthermore, due to the time limit of the data collection process, test-retest was not conducted with the current samples. Therefore, a future study is needed to examine the validity and test-retest reliability of the SAMSAQ-Kr with a large number of student-athletes from many different sports.

Although the SAMSAQ-Kr was developed to identify South Korean student-athletes' motives towards athletic and academic achievement, the questionnaire was based on university athletes. Since younger student-athletes' balance between sport and education is considered an essential element of their life development, a questionnaire or modification of the SAMSAQ-Kr should be pro- 
duced that can examine student-athletes in earlier life.

There are practical implications of the current study findings for those who work with student-athletes, including university administrators, coaches, and practitioners. The SAMSAQ-Kr could be used by university administrators to monitor university student-athletes athletic and academic motivations during their student time and will help assist academic performance. In addition, practitioners and coaches could consider evaluating athletic identity and academic motivation to help student-athletes maintain a balance between sport and education. Finally, practitioners could also develop student-athletes assistant program based on those evaluations.

In conclusion, although researcher's interest in athletes' dual career has increased, research findings indicated that the study area needs to be examined in many different perspectives. For example, in line with the previous research, tendency of student-athletes' motivations towards athletic and academic achievement from the current study were different compared to findings from student-athletes from other nations in terms of influences of socio-cultural and sport environment. These studies suggested a need of developing measurement tools which can be used in different populations. Findings from the current study supported the idea of a need to developing and validating the SAMSAQ questionnaire when it has been translated to other languages differences are observed between the SAMSAQ-Kr model from those of English, Italian, and Arabic versions. The present study findings might contribute to understanding issues related to athletes' dual career by in Korean student-athletes due to developing the SAQSAQ-Kr which can be used to understand and help athletes to have a balance between sport and education. Additionally, the present study echoed the importance of socio-cultural contexts and support system for student-athletes and suggests developing programs tailored to specific target populations are warranted.

\section{CONFLICT OF INTEREST}

No potential conflict of interest relevant to this article was reported.

\section{ACKNOWLEDGMENTS}

This work was supported by the National Research Foundation of Korea Grant funded by the Korean Government (NRF-2014S 1A5B5A07039469). We would like to thank to Dr. Stuart Flint for his contribution.

\section{REFERENCES}

Anderson CB. Athletic identity and its relation to exercise behavior: Scale development and initial validation. J Sport Exerc Psychol 2004;26:39-56.

Atkinson JW. The mainstream of achievement-oriented activity. In Atkinson JW \& Raynor JO (Eds). Motivation and achievement. New York: Halstead, 1974;13-41.

Bandura A. Self-efficacy: Toward a unifying theory of behavioral change. Psychol Rev 1977;84:191-215.

Brewer BW, Cornelius AE. Norms and factorial invariance of the Athletic Identity Measurement Scale (AIMS). Academic Athletic J 2001;16:103113.

Brewer BW, Van Raalte JL, Linder DE. Athletic identity: Hercules' muscles or Achilles' heel? Int J Sport Psycho1993;24:237-254.

Bruner MW, Munroe-Chandler KJ, Spink KS. Entry into elite sport: A preliminary investigation into the transition experiences of rookie athletes. J Appl Sport Psychol 2008;20:236-252.

Fortes PC, Rodrigues G, Tchantchane A. Investigation of academic and athletic motivation on academic performance among university students. Int J Trade Economics Finance 2010;1:367-372.

Gaston-Gayles JL. The factors structure and reliability of the student athletes' motivation toward sports and academics questionnaire (SAMSAQ). J College Stud Dev 2005;46:317-327.

Guidotti F, Minganti C, Coris C, Piacentini MF, Tessitore LC. Validation of the Italian version of the Student Athlete' Motivation towards Sport and Academics Questionnaire. Sport Sci Health 2013;9:51-58.

Harrison CK, Lawrence SM. Female and male student athletes' perceptions of career transition in sport and higher education: A visual elicitation and qualitative assessment. J Vocat Educ Train 2004;56:485-505.

Hart DL, Wright BD. Development of an index of physical functional health status in rehabilitation. Arch Phys Med Rehabil 2002;83:655665.

Jang J. Research on the reason for the early retirement of college soccer players and change into honor student from soccer players. J Korean Society Study Phys Educ 2010;15:19-33.

Park S, Lavallee D, Tod D.Athletes' career transition out of sport: a systematic review. Int Rev Sport Exerc Psychol 2013;6:22-53.

Si G, Rethorest S, Williamczik K. Casual attribution perception in sports achievement: A cross-cultural study on attributional concepts in Germany and China. J Cross-Cultural Psychol 1995;26:537-553.

Stambulova N, Wrisberg CA, Ryba T. A Tale of Two Traditions in Applied Sport Psychology: The Heyday of Soviet Sport and Wake-Up Calls for North America. J Appl Sport Psychol 2006;18:173-184.

Stephan Y, Brewer BW. Perceived determinants of identification with the athlete role among elite competitors. J Appl Sport Psychol 2008;19:69- 
79.

Su CT, Parham LD. Case report-generating a valid questionnaire translation for cross-cultural use. Am J Occup Ther 2002;56:581-585.

Werthner P, Orlick T. Retirement experiences of successful Olympic athletes. IntJ Sport Psychol 1986;17:337-363.
Wright BD, Linacre JM, Smith RM, HeinemannAW, Granger CV. FIM measurement properties and Rasch model details. Scand J Rehabil Med 1997;29:267-72.

Zhu W, Cole EL. Many-faceted Rasch calibration of a gross motor instrument. Res Q Exerc Sport 1996;67:24-34. 